\title{
Osteocyte Necrosis in Normal Bone
}

\author{
DONALD H. ENLOW \\ Department of Anatomy, The University of Michigan, Ann Arbor, Michigan
}

Bone tissues from a variety of different skeletal elements of 89 healthy rhesus monkeys in an age series were screened for nonpathologic osteocyte necrosis.* Incidence of cellular necrosis was found directly related to the age of the monkey. Virtually no cellular necrosis was found in very young monkeys having primary dentition. Bone samples from about half of the monkeys with mixed dentition, however, had scattered, isolated patches of empty lacunas (Fig. 1). All monkeys with permanent dentition had some degree of necrocytosis, ranging from such scattered patches to relatively extensive zones (Fig. 2).

The incidence of osteocyte necrosis also was found to be related to the extent of vascular canal distribution. In bone tissues containing a dense arrangement of canals, cellular necrosis was not ob-

This study was supported by U.S. Public Health Service Grants D1123 and DE09103 from the National Institute of Dental Research, National Institutes of Health, Bethesda, Md.

Additional information is available on request to the author.

Received for publication December 16, 1964.

* Methods used in this study and a discussion of relationships between bone necrosis and haversian system replacement were presented as a subsidiary part of a previous report dealing with the functional role of the secondary osteone (D. H. ENLow, Am. J. Anat., 110:269-306, 1962).

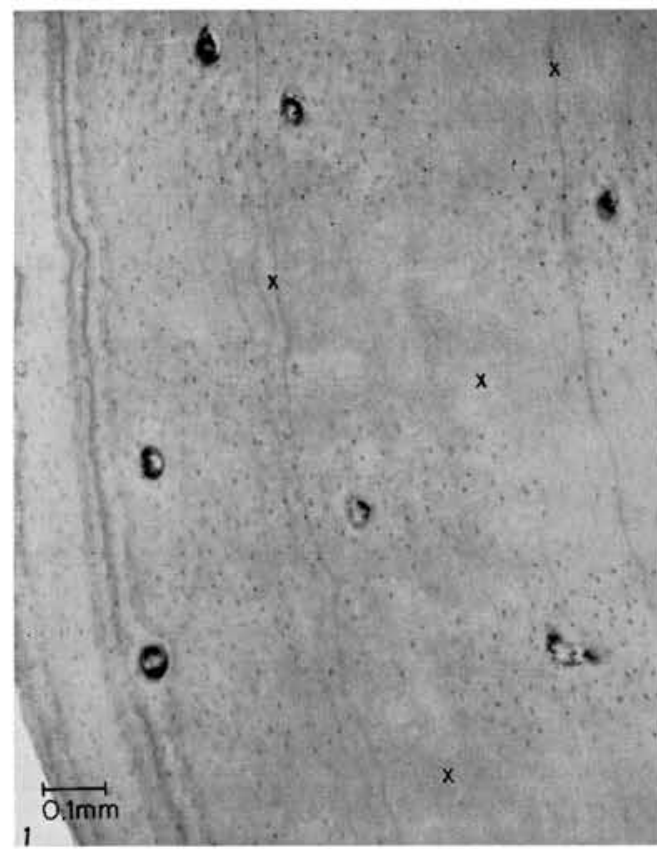

served. Such highly vascular bone tissues were characteristically found in young, growing monkeys. In older monkeys, vascular canals in many parts of the cortex were found to be more widely separated (Fig. 1), and in remote intervascular regions there frequently were empty lacunas.

It is noteworthy that this situation conforms to the "tissue cylinder" concept of Krogh, in which a central blood vessel is responsible for the maintenance of a functional cylinder of tissue surrounding it. A critical cell-to-capillary distance is involved, and if this is exceeded during bone deposition, adequate cell maintenance becomes jeopardized and necrocytosis can result.

Extensive zones of virtually nonvascular bone were observed in some parts of the cortex, and correspondingly extensive necrocytosis was seen in such regions (Fig. 2). Furthermore, some canals were found to be entirely void of cellular and vascular components. Such canals were characteristically surrounded by several layers of empty lacunas (the tissue cylinder). Canals that have been totally occluded by bone deposits were occasionally seen, and these also were surrounded by osteocyte-free lacunas. Also, osteocyte necrosis was observed in interstitial regions between haversian systems.

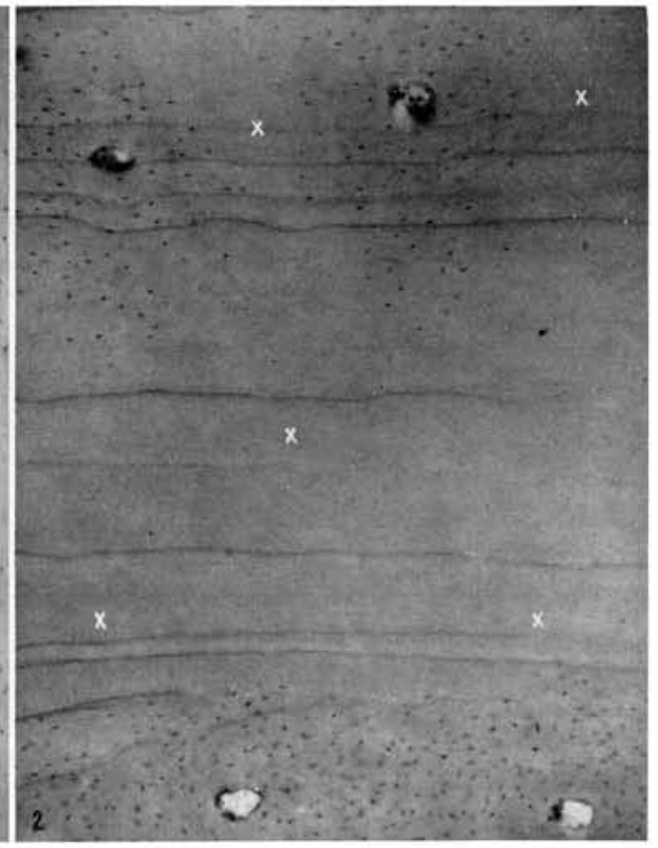

Fig. 1.-Bone sample from a monkey with mixed dentition shows isolated patches of empty lacunas. $X=$ absence of osteocyte nuclei.

FIG. 2.-Bone sample from monkey with permanent dentition shows extensive zone of necrocytosis. $X=$ absence of osteocyte nuclei. 